\title{
Design of a Logistics Nonlinear System for a Complex, Multiechelon, Supply Chain Network with Uncertain Demands
}

\author{
Aaron Guerrero Campanur, ${ }^{1}$ Elias Olivares-Benitez $\mathbb{D D}^{2},{ }^{2}$ Pablo A. Miranda $\left(\mathbb{D},{ }^{3}\right.$ \\ Rodolfo Eleazar Perez-Loaiza, ${ }^{4}$ and Jose Humberto Ablanedo-Rosas $\mathbb{\circledR}^{5}$ \\ ${ }^{1}$ ITSUruapan, Tecnologico Nacional de Mexico, Carr. Uruapan-Carapan 5555, Uruapan, Michoacan 60015, Mexico \\ ${ }^{2}$ Facultad de Ingenieria, Universidad Panamericana, Prolongacion Calzada Circunvalacion Poniente 49, \\ Zapopan, Jalisco 45010, Mexico \\ ${ }^{3}$ Department of Engineering Sciences, Universidad Andres Bello, Quillota 980, Viña del Mar, 2531015, Chile \\ ${ }^{4}$ ITApizaco, Tecnologico Nacional de Mexico, Av. Instituto Tecnológico S/N, Apizaco, Tlaxcala 90300, Mexico \\ ${ }^{5}$ College of Business Administration, University of Texas at El Paso, 500 W. University Avenue, El Paso, TX 79968, USA \\ Correspondence should be addressed to Elias Olivares-Benitez; eolivaresb@up.edu.mx
}

Received 29 June 2018; Revised 3 October 2018; Accepted 28 October 2018; Published 12 November 2018

Academic Editor: Zhiwei Gao

Copyright (C) 2018 Aaron Guerrero Campanur et al. This is an open access article distributed under the Creative Commons Attribution License, which permits unrestricted use, distribution, and reproduction in any medium, provided the original work is properly cited.

\begin{abstract}
Industrial systems, such as logistics and supply chain networks, are complex systems because they comprise a big number of interconnected actors and significant nonlinear and stochastic features. This paper analyzes a distribution network design problem for a four-echelon supply chain. The problem is represented as an inventory-location model with uncertain demand and a continuous review inventory policy. The decision variables include location at the intermediate levels and product flows between echelons. The related safety and cyclic inventory levels can be computed from these decision variables. The problem is formulated as a mixed integer nonlinear programming model to find the optimal design of the distribution network. A linearization of the nonlinear model based on a piecewise linear approximation is proposed. The objective function and nonlinear constraints are reformulated as linear formulations, transforming the original nonlinear problem into a mixed integer linear programming model. The proposed approach was tested in 50 instances to compare the nonlinear and linear formulations. The results prove that the proposed linearization outperforms the nonlinear formulation achieving convergence to a better local optimum with shorter computational time. This method provides flexibility to the decision-maker allowing the analysis of scenarios in a shorter time.
\end{abstract}

\section{Introduction and Context of the Problem}

Supply chain design is a critical strategy for achieving competitiveness in current global business environments. The supply chain consists of all functions involved, directly and indirectly, in meeting customer needs. Decision-making in supply chain management is classified into three hierarchical levels: strategic (long-term), tactical (medium-term), and operational (short-term). Frequently, these decisions are analyzed and solved independently at each planning stage, which generates an overall suboptimal solution when compared to solutions from comprehensive models. Therefore, supply chain management demands the use of new strategies and technologies to meet the current challenges of economic globalization [1], especially the highly dynamic behavior of customer demand. This characteristic imposes a greater challenge in developing and designing responsive and efficient supply chain networks. The mathematical formulation in the operational planning stage is highly critical and must model the relevant characteristics of the supply chain.

Facility location problems, which are typically used to design distribution networks, involve determining the sites where to install resources, as well as the assignment of potential customers to those resources. This family of problems typically assumes a linear cost function and a set of deterministic customer demand. These assumptions avoid modelling interactions between facility location and inventory management decisions. According to these facts, the 


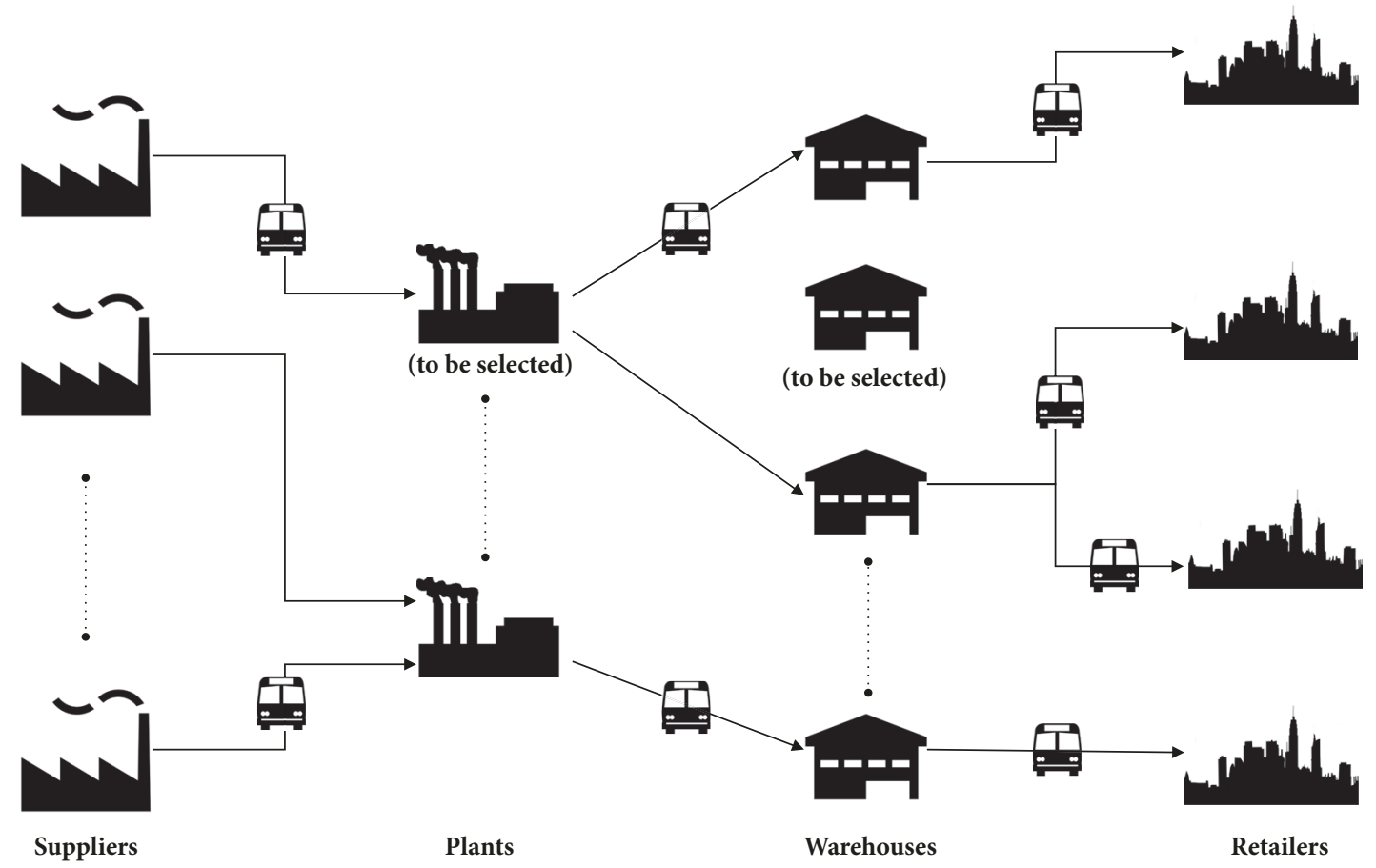

FIGURE 1: Four-echelon supply chain.

inventory-location research literature is aimed to integrate the demand uncertainty and the risk-pooling effect into supply chain network design [2].

This paper presents a mixed integer nonlinear programming formulation aimed to optimize the distribution network design. The model includes decisions on plants and warehouses location, transportation and assignment between facilities (plants-warehouses, warehouses-retailers), supplier selection, and implicit inventory decisions. The model is named a Four-Echelon Inventory-Location Problem with Supplier Selection (4EILP-SS). The mathematical formulation models a four-echelon supply chain, with a set of potential sites for allocation of plants and warehouses, as shown in Figure 1. Each warehouse and plant has a limited capacity and manages a continuous review inventory policy to satisfy the demand of retailers and warehouses, respectively.

The objective is to determine the flow of material in each echelon and the location of plants and warehouses. Inventory management decisions are simultaneously modeled with the design of the distribution network. The problem of locating facilities is commonly used as a base for the design of supply chains. However, the effect of risk integration by inventory management decisions is not directly modeled by the classic facility location problem (FLP). Additionally, supplier selection is a relevant issue because it affects many important aspects of the supply chain performance. In some real cases, for example in the context of the automotive industry, it is common to consider the involvement of suppliers in the supply chain planning stage. Supplier selection is a complex process that involves identifying potential suppliers, requesting information, establishing contract terms, negotiation, and evaluation. Several criteria are considered for supplier selection: quality, delivery time, price, service, and flexibility, among others. In the problem studied, we are assuming that the available suppliers were preselected considering several of the criteria described before, and the last decision was made based on the outcome of the optimization model that considers cost, lead time, and capacity. This is a common practice in industry, especially automotive industry, which is the motivation of this work, where an exclusive group of suppliers has the appropriate certifications by Original Equipment Manufacturers to participate in bids and requests.

Additionally, in the recent years, there has been an offshore moving of automotive manufacturing plants from industrialized countries to emerging economies. This happened in China, India, Mexico, Brazil, Thailand, and Turkey, among others [3]. This required the design of new supply chains to meet the demand, including new plants and warehouses.

The remainder of this paper is organized as follows. Section 2 reviews the relevant literature in supply chain design, with special emphasis on risk integration that results from the integration of an inventory management policy. Section 3 describes the features of the problem and presents two mathematical formulations: a nonlinear mixed integer programming model and a linearization of the aforementioned model using a piecewise linear function to obtain a linear mixed integer programming model. Section 4 presents the experimentation and results for some instances. Lastly, Section 5 presents the conclusions and final remarks. 


\section{Literature Review}

Inventory-location problems (ILPs) have been extensively studied over the past two decades. This section presents a review of the main contributions reported in the literature, showing trends in formulations and solution approaches. Although ILPs are extensions of Facility Location Problems (FLPs), this paper does not discuss the related FLP literature. Interested readers may consult Hamacher and Drezner [4], Daskin [5], Nickel and Puerto [6], Melo et al. [7], and Eiselt and Marianov $[8,9]$.

Jayaraman [10] studied a basic ILP, based on a mixed integer programming model for locating warehouses and satisfying customer's demand for different products. The inventory modeling included the EOQ (Economic Order Quantity) model with fixed lot size and deterministic demand. Nozick and Turnquist [11] investigated an ILP, which included fixed warehouse location costs, and transportation and inventory costs. The problem was solved using a combination of a greedy and improvement algorithm. Erlebacher and Meller [12] presented an ILP with stochastic demands for a two-stage supply chain network, along with some heuristic procedures to solve a variety of instances. Another two-echelon ILP was studied by Nozick and Turnquist [13]. The model minimizes the inventory and unfulfilled demand costs. They used a combination of iterative greedy and improvement algorithms as a solution strategy. Nozick and Turnquist [14] analyzed a distribution system and the trade-off between facility costs, inventory costs, transportation costs, and customer responsiveness. They built an efficient frontier for assessing the different solution configurations.

Daskin et al. [15], Shen et al. [16], and Miranda and Garrido [17] presented similar versions of ILPs, proposing mixed nonlinear integer-programming formulations. The model considers a continuous control inventory policy with stochastic demand, the safety stock cost is determined by a chance-constrained approach, and the ordering decisions are based on the EOQ model with order quantities as decision variables. Daskin et al. [15] and Miranda and Garrido [17] solved the model using Lagrangian relaxation, while Shen et al. [16] reformulated the model as a set-covering problem, and developed a column-generation algorithm. Shu et al. [18] studied the column generation approach proposed by Shen et al. [16], showing that the pricing problem gives rise to a new class of the submodular function minimization problem. They discussed how the general pricing problem could be solved by exploiting certain special structures.

Snyder et al. [19] presented a stochastic programmingbased ILP including some random parameters defined by discrete scenarios. The location model explicitly handles the economies of scale and risk-pooling effects that result from consolidating inventory sites. They used a Lagrangian relaxation-based algorithm. Shu et al. [20] proposed a two-stage stochastic model to address an integrated location, and two-echelon, inventory network design under uncertainty. They defined the problem as a twostage nonlinear discrete optimization problem. The first stage decides which warehouses to open and the second one decides the warehouse-retailer assignments and the two-echelon inventory replenishment. They used a set covering formulation transformed into a pricing problem, which was solved using column generation.

ILPs with inventory capacity constraints were analyzed by Miranda and Garrido [21, 22] and Ozsen et al. [23]. Ozsen et al. [23] introduced a $100 \%$ service level constraint for inventory capacity to a previous ILP presented by Daskin et al. [15], while Miranda and Garrido [21, 22] discussed how the inventory capacity constraint can be controlled by a previously defined service level (usually less than $100 \%)$, based on a chance-constrained formulation. Ozsen et al. [23] and Miranda and Garrido [21, 22] developed a Lagrangian relaxation-based solution approach. Miranda and Cabrera [24] and Cabrera et al. [25] introduced an ILP with periodic inventory control review, where inventory capacity constraints are modeled in a stochastic manner.

Notice that all previous works are focused on optimizing location and inventory costs and decisions are taken at a single stage of the supply chain (i.e., warehouses), along with transport or assignment decisions (plant-warehouses and/or warehouses-retailers). In the works described forward, some additional considerations of costs and operations management decisions are integrated into similar ILP formulations.

Kang and Kim [26] investigated an ILP for warehouse location, integrating inventory costs and assignment decisions at the warehouse and retailers. They formulated a nonlinear mixed integer programming model and developed a Lagrangian relaxation-based heuristic.

Silva and Gao [27] introduced a joint replenishment ILP. They proposed a Greedy Randomized Adaptive Search Procedure to solve the problem. Tancrez et al. [28] studied an ILP in three-level supply chain networks. The decision set included distribution centers location, flows allocation, and shipment sizes. They proposed a nonlinear formulation that decomposes into a closed-form equation and a linear programming model when the distribution center flows are fixed. They developed an iterative heuristic that estimates the distribution center flows a priori, solves the linear program, and then improves the distribution center flows estimations. Similarly, Diabat et al. [29] studied a simplified multiechelon ILP (with location decisions at a single level), where the problem was formulated as a nonlinear mixed integer program and was solved using a Lagrangian relaxation approach.

Shahabi et al. [30] developed a model to coordinate facility location and inventory control in a four-echelon supply chain with hubs, which helps in reducing transportation costs by consolidating shipments. There were three decisions: warehouses and hubs locations, assignment of suppliers and retailers, and inventory control decisions and costs at a single stage (warehouses). A mixed integer nonlinear programming formulation was first presented and then transformed into a compact conic mixed integer programming formulation. Commercial solvers were used to solve the problem.

Shen and Daskin [31], Gaur and Ravindran [32], Miranda and Garrido [33], Mak and Shen [34], and Escalona et al. [35] are a variety of works in which customer or system service levels are integrated and analyzed explicitly based on previous ILP formulations. Genetic Algorithms, Lagrangian 
relaxation, and two-step greedy-based heuristics are some of the approaches employed to solve the analyzed ILPs.

Atamtürk et al. [36] introduced a conic integer programming approach to reformulate a variety of ILPs. These reformulations, for different cases of nonlinearities, can be solved directly using standard optimization software packages without the need for designing specific algorithms. They concluded that their approach led to similar or better computational times than other approaches reported in the literature, and they claimed the applicability of their approach to model more general, related problems.

Kaya and Urek [37] proposed a model for a closed loop supply chain that integrates location, inventory and pricing decisions. The location decision is applied to the level of collection-distribution centers. Inventory is modeled without uncertainty in demand but affected by a pricedemand function. The mixed integer nonlinear programming model is solved using commercial optimization software for small instances, and several heuristics for large instances. The heuristics include a Piecewise linearization, and hybrids of Simulated Annealing, Tabu Search, Genetic Algorithms, and Variable Neighborhood Search.

Schuster Puga and Tancrez [38] analyze a supply chain network with three levels. The flow of product is from a central plant to distribution centers to retailers. Location decisions are applied to the distribution centers. The model developed considers inventory decisions, and transportation costs follow a full truckload approach. They developed an iterative heuristic to solve the continuous nonlinear programming model. Also, they developed a conic quadratic mixedinteger program to transform the original formulation. They solved instances with up to 1000 retailers and 1000 distribution centers.

Escalona et al. [39] studied a supply chain network with three levels and inventory-location decisions. They add a stratification of customers according to classes based on the service level required. The mixed integer nonlinear programming model is transformed into a conic quadratic mixed-integer problem. Their main objective is to analyze the effect of different inventory policies on the configuration of the supply chain network.

Tapia-Ubeda et al. [40] studied an ILP for a supply chain consisting of two levels, with warehouses shipping product to customers. They developed a mixed integer nonlinear programming model to be solved using a Benders Decomposition algorithm. The nonlinear nature of the original model is transferred to the subproblems, but for the instances solved the subproblems can be solved to optimality without a big effort.

It must be noticed that most of the previous ILP formulations integrate location decisions at one or two stages (warehouse location, plant location and supplier selection, warehouse and consolidating center location, etc.). Inventory costs and decisions are modeled at one or two levels (warehouses, warehouses, and plants, warehouses and retailers, etc.), but none of these previous work simultaneously integrates location and inventory management decisions at two stages in the supply chain. Therefore, this research paper fills an important gap in the field of supply chain network design.
To the best of our knowledge, only a previous work by ourselves has considered the design of such a complex supply chain as in this research, with some differences in the model and more important, in the solution method. Perez Loaiza et al. [41] studied a supply chain of four levels with location and inventory decisions and a bi-objective approach. The mixed integer nonlinear programming model is solved using an evolutionary algorithm. Pareto fronts are compared with respect to solutions obtained with commercial optimization software.

The following part of the literature review discusses linearization strategies for nonlinear problems. You and Grossmann [42] addressed an ILP from the chemical industry, the design of a multiechelon supply chain and inventory system in the presence of uncertain customer demands. A mixed integer nonlinear program modeled the transportation, inventory, and network structure of a multiechelon supply chain. The model had a non-convex objective function. They reformulated the problem as a separable concave program. A spatial decomposition algorithm based on the integration of Lagrangian relaxation and piecewise linear approximation was proposed to solve the model. The transformation assures all the constraints are linear and the only nonlinear terms are univariate concave terms in the objective function. Petridis [43] addressed a multiproduct, multiechelon supply chain network with demand uncertainty. Decisions about the selection of facilities and their capacity are made. Information about the flows of products transferred and the safety stock at each distribution center was derived. The lead time of an order to a customer is computed, using the probabilities of overstocking and understocking. The problem was formulated as a single period mixed integer nonlinear programming problem. Linearization techniques for selected nonlinear terms of the models were explored in order to reduce the computational effort for solving the model. The linearization was achieved by rewriting one of the nonlinear constraints that had a product of a continuous and a binary variable. The objective function was not linearized.

According to the discussed literature review, this paper contributes with an inventory-location model, under continuous review policy, to optimize a four-echelon supply chain network, encompassing multiple suppliers, plants, warehouses, and retailers. The problem is formulated as a mixed integer nonlinear programming model, considering a single item, with stochastic demands across de supply chain network. Decision variables include warehouse and plant location, plant-warehouse assignments, retailer assignment to warehouses, and shipments from suppliers to plants. This ILP integrates inventory costs and decisions at plants and warehouses. As it can be observed from the related literature, the proposed network design model of a four-echelon supply chain has a nonlinear formulation that arises when inventory aspects are integrated into facility location problems, yielding to a nonlinear mixed integer programming model.

Nonlinear mixed integer programming models are extremely hard to solve to optimality, particularly when commercial optimization solvers are employed. They combine the mixed integer programming (NP-Hard) nature with nonlinear and non-convex components. In many cases, researchers 


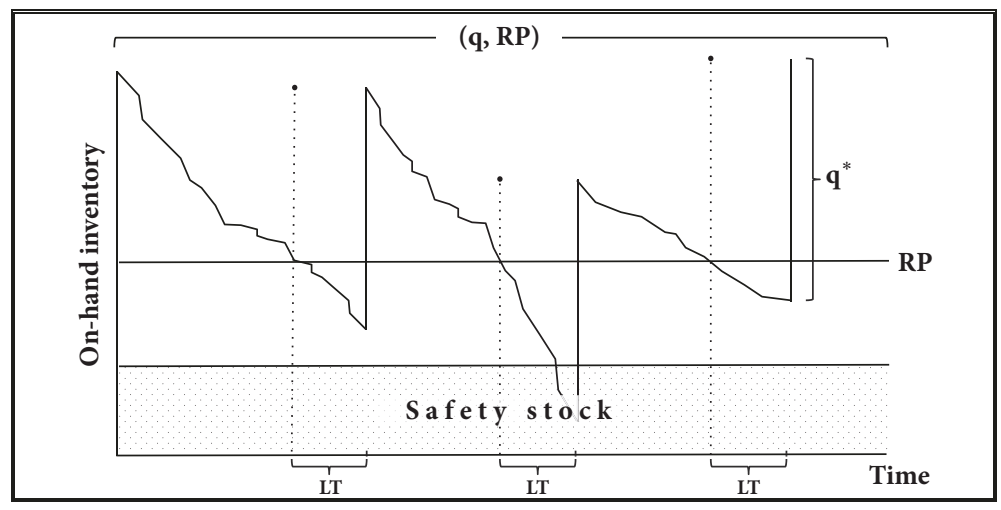

FIGURE 2: Continuous review inventory control policy performance.

and practitioners face two major challenges: local optimum solutions and prohibitive computational times for tackling practical problems. Moreover, these challenges increase when more stages and decision variables are added to the model, such as in this research article. In order to reduce the computational effort, and as a strategy to develop a heuristic framework to tackle this complex problem, a linearization of the model is proposed based on a piecewise linear approximation of the objective function, and a linear reformulation of nonlinear constraints, yielding to a mixed integer linear programming model. The approach is developed following the approach proposed by Diabat and Theodorou [44], who applied this technique in a smaller supply chain network with less supply chain stages and decisions.

\section{Problem Description and Modeling}

3.1. Continuous Review Based Inventory Control Policy $(q, R P)$. A continuous review based inventory control policy $(q, R P)$ is assumed at plants and warehouses with the aim of dealing with uncertain and stochastic demands (warehouses deal with retailer demands and plants deal with warehouse demands or orders). Figure 2 shows the evolution of the physical inventory level when this inventory control policy is assumed. When the inventory level reaches reorder point $R P$, an order of $q$ units of the product is requested. The $q$ units of product are received after a fixed and known lead time $L T$. In other words, $R P$ is the critical inventory level that generates a new order. In the case of warehouses, they generate an order to plants, while in the case of plants they generate a production order or batch. In both cases, a widely accepted approach states that the reorder point at each location, $R P$, must be set in order to ensure that served demand arising during lead time $L T$ will not be greater than this reorder point, at least with a fixed and known probability. This probability is also known as inventory service level.

The existing inventory level just before the order arrives at each location is known as the safety stock, while the inventory level that is observed over the safety stock is known as cyclic or working inventory.
Warehouse demand depends on customers $l$ assigned to each warehouse $k$, and plant demand depends on warehouses assigned to each plant $j$.

To calculate the working inventory cost (WIC), the total inventory cost is estimated by

$$
\begin{gathered}
\text { Total inventory cost }=U C \cdot d+O C \cdot\left(\frac{d}{q}\right)+H C \\
\cdot\left(\frac{q}{2}\right),
\end{gathered}
$$

where $U C$ is the purchasing cost, $d$ is the demand, $q$ is the order quantity, $O C$ is the ordering cost, and $H C$ is the inventory holding cost. The first derivative of (1) with respect to $q$ is obtained, equal to zero, and solved for $q^{*}$. The optimal order quantity $q^{*}$ is obtained as

$$
q^{*}=\sqrt{\frac{2 \cdot d \cdot O C}{H C}}
$$

Then, the working inventory costs WIC, the last component of (1), is obtained using $q^{*}$ from (2) in

$$
W I C=H C \cdot \frac{q^{*}}{2}=\sqrt{2 \cdot O C \cdot H C \cdot d} .
$$

Assuming an uncertain demand with normal distribution, the reorder point $R P$ can be calculated according to

$$
\operatorname{Prob}(d(L T) \leq R P)=1-\alpha,
$$

such that

$$
R P=d \cdot L T+Z T \cdot \sqrt{u \cdot L T},
$$

where $Z T$ represents the value of the Standard Normal Distribution $(0,1)$ that accumulates a probability of $1-\alpha$ (service level). This value of $Z T$ in (5) determines the safety stock level at each facility. The variance of the demand is given by $u$, and $L T$ represents the lead time.

$R P$ is the amount of inventory that should be available in each plant and warehouse to absorb fluctuations in demand from retailers during the lead time. Safety stock is the carried 
out inventory to prevent stock outs. It describes the balance between the cost of holding inventory and profit foregone as a result of outages. In this case, it was not considered the cost of not having stock, only the safety stock cost (SSC) in each plant or warehouse. SSC is given by

$$
S S C=Z T \cdot H C \cdot \sqrt{u \cdot L T} .
$$

A similar explanation of these terms can be found in Daskin et al. [15] and Shen et al. [16].

3.2. Description of the Model Formulation. In this section, the mathematical formulation of the problem studied in this paper is presented. Section 3.2.1 discusses the mixed integer nonlinear model for distribution network design, 4EILP-SS. The linearization process for the constraints is explained in this section too. Section 3.2.2 illustrates the linearization process of both safety stock and working inventory costs using an approximation based on piecewise linear functions; thereby a mixed integer linear model is obtained (4EILP-SS$\mathrm{L})$. The motivation to linearize the original model is based on the characteristics of commercial optimization software. In most of the cases, the standard methods used to solve nonlinear models do not guarantee to find a global optimum solution, and when this is possible the computational time may be too long and unreasonable.

\subsubsection{Mixed Integer Nonlinear Model}

\section{Notation and Definitions}

Sets

$I$ : Set of suppliers, $i=1,2, \ldots,|I|$.

$J$ : Set of potential plant locations, $j=1,2, \ldots,|J|$.

$K$ : Set of potential warehouse locations, $k=$ $1,2, \ldots,|K|$.

$L:$ Set of retailers, $l=1,2, \ldots,|L|$.

\section{Parameters}

$c s_{i}$ : Production capacity of supplier $i$.

$c w_{k}$ : Maximum capacity of warehouse $k$.

$c p_{j}$ : Maximum capacity of plant $j$.

$d_{l}$ : Average demand for each retailer $l$.

$F C p_{j}$ : Fixed cost of opening a plant at site $j$.

$F C w_{k}$ : Fixed cost of opening a warehouse at site $k$.

$H C_{j}^{p}$ : Inventory holding cost per unit in plant $j$.

$H C_{k}^{w}$ : Inventory holding cost per unit in warehouse $k$.

$L T_{j}^{p}$ : Deterministic delivery lead time to plant $j$.
$L T_{k}^{w}$ : Deterministic delivery lead time to warehouse $k$.

OC ${ }_{j}^{p}$ : Ordering cost at plant $j$.

$O C_{k}^{w}$ : Ordering cost at warehouse $k$.

$T C_{i j}^{a}$ : Transportation cost per unit from supplier $i$ to plant $j$.

$T C_{j k}^{b}$ : Transportation cost per unit from plant $j$ to warehouse $k$.

$T C_{k l}^{c}$ : Transportation cost per unit from warehouse $k$ to retailer $l$.

$U C_{i}^{s}$ : Purchase cost per unit at supplier $i$.

$u_{l}$ : Demand variance at retailer $l$.

$Z_{1-\alpha}$ : Values of $Z T$ for a given service level, assuming a Normal Distribution.

$\tau_{j}$ : Working inventory cost at plant $j$.

$\varphi_{j}$ : Safety stock at plant $j$.

$\psi_{k}$ : Working inventory cost at warehouse $k$.

$\omega_{k}$ : Safety stock at warehouse $k$.

\section{Decision Variables}

$x_{k}: 1$ if warehouse $k$ is opened; 0 otherwise.

$y_{j}: 1$ if plant $j$ is opened; 0 otherwise.

$w_{j k}: 1$ if plant $j$ serves warehouse $k$; 0 otherwise.

$z_{k l}: 1$ if warehouse $k$ serves retailer $l ; 0$ otherwise.

$\beta_{i j}$ : Number of units of product produced by supplier $i$ and shipped to plant $j$.

Auxiliary Variables

$\delta_{j}$ : Average demand assigned to plant $j$.

$\eta_{j}$ : Demand variance assigned to plant $j$.

$\lambda_{k}$ : Average demand assigned to warehouse $k$.

$\pi_{k}$ : Demand variance assigned to warehouse $k$.

$\tau_{j}$ : Product of ordering cost, inventory holding cost and demand assigned to plant $j$.

$\varphi_{j}$ : Product of lead time and demand variance assigned to plant $j$

$\psi_{k}$ : Product of ordering cost, inventory holding cost and demand assigned to warehouse $k$.

$\omega_{k}$ : Product of lead time and demand variance assigned to warehouse $k$. lated as

Thus, the mathematical model for the problem is formu-

$\min \mathrm{Z} 1$

$$
=\sum_{j=1}^{|J|}\left(F C p_{j} \cdot y_{j}+\sqrt{\tau_{j}}+Z_{1-\alpha} \cdot H C_{j}^{p} \cdot \sqrt{\varphi_{j}}+\sum_{i=1}^{|I|}\left(\left(U C_{i}^{s}+T C_{i j}^{a}\right) \cdot \beta_{i j}\right)+\sum_{k=1}^{|K|}\left(T C_{j k}^{b} \cdot \lambda_{k} \cdot w_{j k}\right)\right)
$$




$$
+\sum_{k=1}^{|K|}\left(F C w_{k} \cdot x_{k}+\sqrt{\psi_{k}}+Z_{1-\alpha} \cdot H C_{k}^{w} \cdot \sqrt{\varpi_{k}}+\sum_{l=1}^{|L|}\left(T C_{k l}^{c} \cdot d_{l} \cdot z_{k l}\right)\right)
$$

$$
\begin{aligned}
\text { subject to } & \sum_{k=1}^{|K|} z_{k l}=1, \quad \forall l=1, \ldots,|L|, \\
& \sum_{j=1}^{|J|} w_{j k}=x_{k}, \quad \forall k=1, \ldots,|K|, \\
& \sum_{i=1}^{|I|} \beta_{i j} \geq y_{j}, \quad \forall j=1, \ldots,|J|, \\
& \sum_{l=1}^{|L|} d_{l} \cdot z_{k l}=\lambda_{k}, \quad \forall k=1, \ldots,|K|, \\
& \sum_{l=1}^{|L|} u_{l} \cdot z_{k l}=\pi_{k}, \quad \forall k=1, \ldots,|K|, \\
& \sum_{k=1}^{|K|} \lambda_{k} \cdot w_{j k}=\delta_{j}, \quad \forall j=1, \ldots,|J|, \\
& \sum_{k=1}^{|K|} \pi_{k} \cdot w_{j k}=\eta_{j}, \quad \forall j=1, \ldots,|J|, \\
& \sum_{i=1}^{|I|} \beta_{i j}=\delta_{j}, \quad \forall j=1, \ldots,|J|, \\
& \tau_{j}=2 \cdot O C_{j}^{p} \cdot H C_{j}^{p} \cdot \delta_{j}, \quad \forall j=1, \ldots,|J|, \\
& \varphi_{j}=L T_{j}^{p} \cdot \eta_{j}, \quad \forall j=1, \ldots,|J|, \\
& \psi_{k}=2 \cdot O C_{k}^{w} \cdot H C_{k}^{w} \cdot \lambda_{k}, \quad \forall k=1, \ldots,|K|, \\
& \omega_{k}=L T_{k}^{w} \cdot \pi_{k}, \quad \forall k=1, \ldots,|K|, \\
& \lambda_{k} \leq c w_{k} \cdot x_{k}, \quad \forall k=1, \ldots,|K|, \\
& |J| \\
j=1 & \beta_{i j} \leq c s_{j}, \quad \forall i=1, \ldots, y_{j}, \quad \forall j=1, \ldots,|J|, \\
& \\
&
\end{aligned}
$$

The objective function of the optimization model, 4EILP-SS, is to minimize the total cost given by the cost components in (7). These components represent the fixed cost if plant $j$ and warehouse $k$ are open, the cost of safety stock and working inventory at each plant and warehouse, the purchase and transportation cost to serve the average demand shipped from supplier $i$ to plant $j$, and the transportation cost from plant $j$ to warehouse $k$ and from there to retailer $l$. Equation (8) ensures that each retailer is served exactly by one warehouse. Constraints in (9) guarantee that each opened warehouse is served only by one plant. These constraints follow the single source assumption used frequently in the 
literature and practice. Equation (10) indicates that suppliers should ship at least one unit to open plants. Equations (11) and (12) compute the transferred demand average and variance from retailers to warehouses. Similarly, nonlinear constraints in (13) and (14) compute the demand average and its variance transferred from warehouses to plants. Equation (15) meets the demand from suppliers to plants. Equations (16) to (19) calculate auxiliary variables used into the objective function. Their use is not essential at this point, but these equations are helpful later to address the nonlinearity of the model. Inequalities in (20), (21), and (22) ensure that the capacities of the warehouses, plants, and suppliers are not exceeded, respectively, for open facilities. Finally, (23) and (24) show the nature of the variables.

A reformulation of the constraints in (13) and (14) is presented forward. In these constraints, the product of an integer auxiliary variable and a binary decision variable occurs, for instance $\lambda_{k}$ and $w_{j k}$ in (13). Combining (13) and (11), the first can be reformulated as

$$
\sum_{k=1 l=1}^{|K|} \sum_{l}^{|L|} d_{l} \cdot w_{j k} \cdot z_{k l}=\delta_{j}, \quad \forall j=1, \ldots|J| .
$$

Nonlinear constraints are produced by the product of two binary decision variables, i.e., $w_{j k} \cdot z_{k l}$. The nonlinearity in (25) is removed when

$$
\begin{aligned}
& v_{j k l} \geq w_{j k}+z_{k l}-1, \\
& \forall j=1, \ldots|J|, \quad \forall k=1, \ldots|K|, \forall l=1, \ldots|L|, \\
& v_{j k l} \leq w_{j k}, \\
& \forall j=1, \ldots|J|, \forall k=1, \ldots|K|, \forall l=1, \ldots|L|, \\
& v_{j k l} \leq z_{k l} \text {, } \\
& \forall j=1, \ldots|J|, \quad \forall k=1, \ldots|K|, \forall l=1, \ldots|L|,
\end{aligned}
$$

are added, with the introduction of a binary variable $v_{j k l}$, such that if $w_{j k}=1$ and $z_{k l}=1$, then variable $v_{j k l}=1$, and otherwise $v_{j k l}$ may take the value of zero [45].

If $w_{k l} \cdot z_{j k}$ is substituted by $v_{j k l}$ in (25), the result will be the linear constraints

$$
\sum_{k=1 l=1}^{|K|} \sum_{l}^{|L|} d_{l} \cdot v_{j k l}=\delta_{j}, \quad \forall j=1, \ldots|J|,
$$

instead of those in (13). The constraints in (29) involve the product of a parameter $d_{l}$ and a binary decision variable $v_{j k l}$. Using the same procedure, constraints in (14) are reformulated and presented as

$$
\sum_{k=1 l=1}^{|K|} \sum_{l}^{|L|} u_{l} \cdot v_{j k l}=\eta_{j}, \quad \forall j=1, \ldots|J| .
$$

Once a solution for the model is obtained, the order quantity and reorder point at each open facility can be calculated. Using the results for variables $\delta_{j}$ as demands for plants, with their corresponding values for the ordering cost and holding

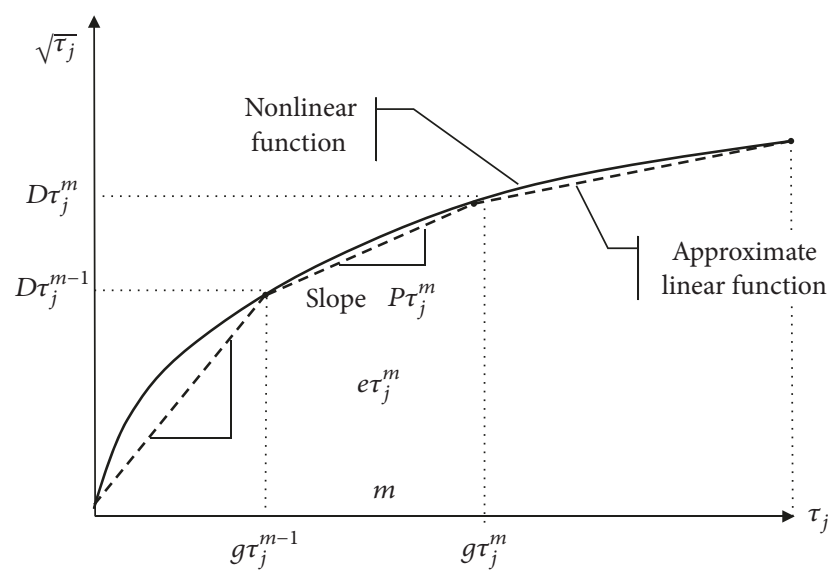

Figure 3: Piecewise linear function PLF of WIC.

cost, the order quantity at each plant can be calculated using (2). Using the results for variables $\delta_{j}$ as demands and $\eta_{j}$ as demand variances for plants, with their corresponding values for the lead time and service level factor, the reorder point at each plant can be calculated using (5). The same can be done for warehouses using the values of $\lambda_{k}$ as demands and $\pi_{k}$ as demand variances.

3.2.2. Linear Approximation of the Objective Function. This section presents a linear approximation approach for the safety stock costs SSC and working inventory costs WIC. WIC in plant $j$ is calculated as $\sqrt{\tau_{j}}$, as derived from (3) and (16). The approximation is based on a piecewise linear function $(P L F)$ defined by two or more straight-lines, presented in different sections of the domain of the function as shown in Figure 3.

Considering a partition of $\tau_{j}$ in $M$ sections, the function $\sqrt{\tau_{j}}$ is approximated linearly by the expression $D \tau_{j}^{m-1} \cdot e \tau_{j}^{m}+$ $P \tau_{j}^{m} \cdot g \tau_{j}^{m}$, where $D \tau_{j}^{1}<D \tau_{j}^{2}<D \tau_{j}^{3} \ldots<D \tau_{j}^{m}$ and $P \tau_{j}^{1}>$ $P \tau_{j}^{2}>P \tau_{j}^{3} \ldots>P \tau_{j}^{m}$, for $m=1, \ldots M$ sections. Here, $g \tau_{j}^{m}$ is the value of $\tau_{j}$ at the upper bound of section $m, D \tau_{j}^{m}$ is the value of $\sqrt{\tau_{j}}$ at the upper bound of section $m, P \tau_{j}^{m}$ is the slope along the section $m, e \tau_{j}^{m}$ is equal to 1 if section $m$ of the piecewise linear function of $\sqrt{\tau_{j}}$ is used or 0 otherwise. Also, $f \tau_{j}^{m}=\tau_{j}-g \tau_{j}^{m-1}$ are the units of $\tau_{j}$ in any point along section $m$.

The linear approximation of WIC at each plant is given by

$$
\begin{aligned}
& \sum_{m=1}^{|M|}\left(D \tau_{j}^{m-1} \cdot e \tau_{j}^{m}+P \tau_{j}^{m} \cdot f \tau_{j}^{m}\right) \approx \sqrt{\tau_{j}}, \\
& \forall j=1, \ldots|J|, \\
& \sum_{m=1}^{|M|}\left(f \tau_{j}^{m}+g \tau_{j}^{m-1} \cdot e \tau_{j}^{m}\right)=\tau_{j}, \quad \forall j=1, \ldots|J|, \\
& f \tau_{j}^{m}<\left(g \tau_{j}^{m}-g \tau_{j}^{m-1}\right) \cdot e \tau_{j}^{m}, \\
& \forall j=1, \ldots|J|, \quad \forall m=1, \ldots|M|,
\end{aligned}
$$


TABLE 1: Parameters of the base case, associated with suppliers $i$.

\begin{tabular}{|c|c|c|c|c|c|c|c|c|c|c|}
\hline Parameter & $i=1$ & $i=2$ & $i=3$ & $i=4$ & $i=5$ & $i=6$ & $i=7$ & $i=8$ & $i=9$ & $i=10$ \\
\hline$c s_{i}=$ & 85 & 70 & 90 & 80 & 75 & 65 & 70 & 71 & 66 & 66 \\
\hline$U C_{i}^{s}=$ & 30 & 28 & 30 & 28 & 24 & 25 & 28 & 21 & 28 & 30 \\
\hline
\end{tabular}

TABLE 2: Parameters of the base case, associated with plants $j$, and warehouses $k$.

\begin{tabular}{|c|c|c|c|c|c|c|c|c|c|}
\hline Plant & $j=1$ & $j=2$ & $j=3$ & Warehouse & $k=1$ & $k=2$ & $k=3$ & $k=4$ & $k=5$ \\
\hline$c p_{j}=$ & 150 & 200 & 110 & $c w_{k}=$ & 70 & 80 & 75 & 70 & 85 \\
\hline$F C p_{j}=$ & 187500 & 250000 & 137500 & $F C w_{k}=$ & 131250 & 150000 & 97500 & 131250 & 121875 \\
\hline$H C_{j}^{p}=$ & 167 & 134 & 164 & $H C_{k}^{w}=$ & 184 & 220 & 190 & 189 & 205 \\
\hline$L T_{j}^{p}=$ & 1 & 3 & 2 & $L T_{k}^{w}=$ & 2 & 1 & 2 & 1 & 2 \\
\hline$O C_{j}^{p}=$ & 646 & 657 & 656 & $O C_{k}^{w}=$ & 743 & 850 & 552 & 743 & 690 \\
\hline
\end{tabular}

TABLE 3: Parameters of the base case, demand, and variance of retailers $l$.

\begin{tabular}{lcccccccccccccc}
\hline Retailer & $l=1$ & $l=2$ & $l=3$ & $l=4$ & $l=5$ & $l=6$ & $l=7$ & $l=8$ & $l=9$ & $l=10$ & $l=11$ & $l=12$ & $l=13$ \\
\hline Demand $\left(d_{l}\right)=$ & 5 & 10 & 10 & 6 & 8 & 5 & 13 & 23 & 12 & 10 & 6 & 7 & 20 \\
Variance $\left(u_{l}\right)=$ & 46 & 40 & 25 & 30 & 87 & 50 & 55 & 65 & 30 & 68 & 70 & 76 & 30 \\
\hline Retailer & $l=14$ & $l=15$ & $l=16$ & $l=17$ & $l=18$ & $l=19$ & $l=20$ & $l=21$ & $l=22$ & $l=23$ & $l=24$ & $l=25$ \\
\hline Demand $\left(d_{l}\right)=$ & 10 & 20 & 9 & 17 & 15 & 15 & 24 & 5 & 25 & 23 & 16 & 14 & 73 & 45 \\
Variance $\left(u_{l}\right)=$ & 35 & 86 & 40 & 50 & 25 & 10 & 60 & 68 & 40 & 73 & 50 \\
\hline
\end{tabular}

TABLE 4: Parameters of the base case, transportation unit cost from supplier $i$ to plant $j$.

\begin{tabular}{lcccccccccc}
\hline$T C_{i j}^{a}$ & $i=1$ & $i=2$ & $i=3$ & $i=4$ & $i=5$ & $i=6$ & $i=7$ & $i=8$ & $i=9$ & $i=10$ \\
\hline$j=1$ & 164 & 151 & 117 & 132 & 153 & 139 & 158 & 151 & 115 & 182 \\
$j=2$ & 140 & 123 & 189 & 162 & 136 & 123 & 132 & 136 & 143 & 167 \\
$j=3$ & 137 & 155 & 120 & 119 & 167 & 134 & 133 & 127 & 180 & 132 \\
\hline
\end{tabular}

$\sum_{m=1}^{|M|} e \tau_{j}^{m}=y_{j}, \quad \forall j=1, \ldots|J|$

$e \tau_{j}^{m}, y_{j} \in\{0,1\}$

$f \tau_{j}^{m} \geq 0$

$$
\forall j=1, \ldots|J|, \forall m=1, \ldots|M|
$$

Equation (31) represents the linear approximation of the WIC at plant $j$. Equation (32) ensures that the average demand in plant $j$ is considered for the linear approximation. Equation (33) establishes that only a section $m$ must be used in the linear approximation. Equation (34) guarantees that the linear approximation is carried out only in open plants. Finally, (35) describes the domain of the variables. The same analysis is considered to generate the linear approximation of SSC in each plant and WIC and SSC in each warehouse.

An alternative objective function $\mathrm{Zl}^{\prime}$ is defined. $\mathrm{Zl}^{\prime}$ is equivalent to $\mathrm{Z} 1$ but considering the linear approximation of WIC and SSC introduced before. The new optimization model, with objective function $\mathrm{Z1}^{\prime}$ and all the linearized constraints, is named 4EILP-SS-L.
TABle 5: Parameters of the base case, transportation unit cost from plant $j$ to warehouse $k$.

\begin{tabular}{lccccc}
\hline$T_{j k}^{b}$ & $k=1$ & $k=2$ & $k=3$ & $k=4$ & $k=5$ \\
\hline$j=1$ & 164 & 140 & 137 & 132 & 162 \\
$j=2$ & 151 & 123 & 155 & 153 & 136 \\
$j=3$ & 117 & 189 & 120 & 119 & 167 \\
\hline
\end{tabular}

\section{Results and Discussion}

In this section, five instance sizes with 10 cases each one are presented. The code of the instance size indicates the number of suppliers followed by the number of potential plants, followed by the number of potential warehouses, and the number of retailers. For example, instance size 53-5-10 indicates 5 suppliers, 3 potential plants, 5 potential warehouses, and 10 retailers.

A commercial license of LINGO 14 was used to solve every case, with the nonlinear and linear models. The nonlinear model corresponds to the formulation described by (7) to (24). The linear model corresponds to the linearization of the objective function and the constraints applied to the original nonlinear model. A service level of $95 \%$ was considered for all the cases. Tables 1-6 show the parameters values of the 


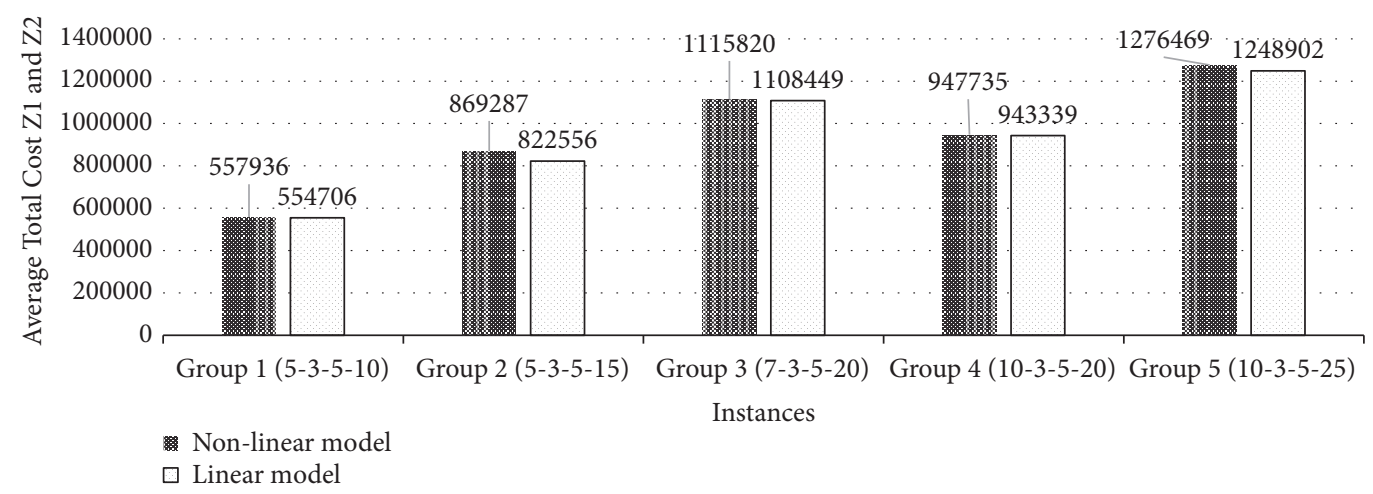

Figure 4: Average total cost, comparing the nonlinear versus the linear models.

TABLE 6: Parameters of the base case, transportation unit cost from warehouses $k$ to retailer $l$.

\begin{tabular}{|c|c|c|c|c|c|}
\hline$T C_{k l}^{c}$ & $k=1$ & $k=2$ & $k=3$ & $k=4$ & $k=5$ \\
\hline$l=1$ & 94 & 70 & 78 & 100 & 93 \\
\hline$l=2$ & 99 & 86 & 86 & 90 & 89 \\
\hline$l=3$ & 86 & 83 & 98 & 80 & 97 \\
\hline$l=4$ & 75 & 90 & 77 & 78 & 91 \\
\hline$l=5$ & 72 & 75 & 77 & 83 & 87 \\
\hline$l=6$ & 80 & 80 & 71 & 99 & 83 \\
\hline$l=7$ & 90 & 74 & 98 & 94 & 99 \\
\hline$l=8$ & 75 & 75 & 87 & 72 & 98 \\
\hline$l=9$ & 74 & 94 & 79 & 80 & 95 \\
\hline$l=10$ & 90 & 80 & 84 & 75 & 99 \\
\hline$l=11$ & 79 & 95 & 96 & 97 & 79 \\
\hline$l=12$ & 84 & 68 & 65 & 97 & 74 \\
\hline$l=13$ & 78 & 74 & 95 & 89 & 75 \\
\hline$l=14$ & 81 & 73 & 84 & 82 & 89 \\
\hline$l=15$ & 98 & 88 & 100 & 98 & 90 \\
\hline$l=16$ & 77 & 78 & 98 & 70 & 95 \\
\hline$l=17$ & 72 & 85 & 70 & 90 & 66 \\
\hline$l=18$ & 98 & 98 & 84 & 86 & 89 \\
\hline$l=19$ & 93 & 65 & 83 & 90 & 90 \\
\hline$l=20$ & 94 & 71 & 75 & 94 & 90 \\
\hline$l=21$ & 89 & 71 & 84 & 85 & 82 \\
\hline$l=22$ & 73 & 80 & 76 & 86 & 80 \\
\hline$l=23$ & 87 & 84 & 79 & 80 & 70 \\
\hline$l=24$ & 81 & 73 & 71 & 70 & 85 \\
\hline$l=25$ & 87 & 83 & 89 & 70 & 72 \\
\hline
\end{tabular}

base case, which were varied to construct the different cases. The case base has 10 potential suppliers, 3 potential plants, 5 potential warehouses, and 25 potential retailers. For example, to generate one instance of the size 5-3-5-10, 5 out of the 10 available suppliers in the base case were selected randomly, the 3 plants are used, the 5 warehouses are used, and 10 out of the 25 retailers were selected randomly from the base case. To generate one instance of the size 7-3-5-20, 7 out of the 10 available suppliers in the base case were selected randomly, the 3 plants are used, the 5 warehouses are used, and 20 out of the 25 retailers were selected randomly from the base case.

The uncertainty in demand is represented by the variance values shown in Table 3. In all the instances of the linear model, four intervals were used for the linearization, following the results from Diabat and Theodorou [44].

Table 7 shows the computational results of applying the nonlinear and the linear model with a service level of $95 \%$ $\left(Z T_{(0.95)}=1.64\right)$. Table 7 shows the objective function value $\mathrm{Zl}$, the saved cost from the comparison, the \% saving with respect to the solution of the nonlinear model, the run elapsed time for the solution with the linear model, and the cases where the solution was obtained only with the linear model. The comparison denotes the significant benefit (\% Saving) that can be obtained by using the linear model instead of the nonlinear model. In this study, the average elapsed run time from the solutions of the linear model was set as a time limit on each group of instances when solving the nonlinear model. In the last column in Table 7, the cases where the nonlinear model does not converge (in the time limit) are shown as well. In order to make a fair comparison between both models, the total cost Z2 was obtained by using the values of the solution obtained by the linear model that optimizes $\mathrm{Zl}$ ' but evaluated in the original objective function $Z 1$. Let $X$ ' be the optimal solution of 4EILP-SS-L, then Z2 = Z1 (X').

Table 8 shows the structure of the supply chain according to the results obtained with the models. In many cases, the structures are very similar, but the assignments between customers and warehouses, warehouses and plants, and flows from suppliers produced the differences in costs.

Figure 4 shows the comparison of the average total cost of the nonlinear and the linear models, where a solution was found. In all cases, the solutions of the linear model are cheaper than the solutions from the nonlinear model. The range of the average percent savings (\% saving) is from $0.51 \%$ to $5.11 \%$. The results of the nonlinear model may be better using a more efficient nonlinear optimizer, especially for the small instances, but it is expected that the linear model will be more efficient for larger instances.

The comparison of the number of solutions obtained between the linear and nonlinear model is presented in Figure 5. The nonlinear model does not converge in all cases with a similar run time than the linear model. The range 
TABLE 7: Results of applying the nonlinear model and the linear model considering a service level of 95\%.

\begin{tabular}{|c|c|c|c|c|c|c|}
\hline \multirow{2}{*}{$\begin{array}{l}\text { Case \# } \\
\text { (Instance size) }\end{array}$} & \multicolumn{2}{|c|}{ Non-Linear Model 4EILP-SS } & \multicolumn{2}{|c|}{ Linear Model 4EILP-SS-L } & \multicolumn{2}{|c|}{ Saving } \\
\hline & $\begin{array}{l}\text { Best found objective } \\
\text { function value }(\mathrm{Zl})\end{array}$ & $\begin{array}{l}\text { Elapsed run time } \\
(\mathrm{sec})\end{array}$ & $\begin{array}{l}\text { Best found objective } \\
\text { function value (Z2) }\end{array}$ & $\begin{array}{l}\text { Elapsed run time } \\
(\mathrm{sec})\end{array}$ & Saved Cost & \% Saving \\
\hline Case 1 ( 5-3-5-10) & 523,690 & 5.05 & 499,861 & 2.86 & 23,829 & $4.55 \%$ \\
\hline Case $2(5-3-5-10)$ & 451,963 & 58.68 & 451,021 & 3.92 & 942 & $0.21 \%$ \\
\hline Case $3(5-3-5-10)$ & 589,253 & 490.76 & 589,246 & 42.80 & 7 & $0.00 \%$ \\
\hline Case 4 (5-3-5-10) & 734,372 & 273.47 & 733,524 & 65.91 & 848 & $0.12 \%$ \\
\hline Case 5 (5-3-5-10) & 514,842 & 396.13 & 514,842 & 3.64 & 0 & $0.00 \%$ \\
\hline Case 6 (5-3-5-10) & 506,738 & 13.35 & 505,464 & 11.79 & 1,274 & $0.25 \%$ \\
\hline Case 7 (5-3-5-10) & 511,549 & 116.7 & 511,549 & 8.71 & 0 & $0.00 \%$ \\
\hline Case 8 (5-3-5-10) & 517,406 & 98.01 & 517,406 & 10.56 & 0 & $0.00 \%$ \\
\hline Case 9 (5-3-5-10) & 639,303 & 213.99 & 639,303 & 83.68 & 0 & $0.00 \%$ \\
\hline Case 10 (5-3-5-10) & 584,845 & 48.24 & 584,845 & 15.37 & 0 & $0.00 \%$ \\
\hline AVERAGE & 557,396 & 171.44 & 554,706 & 24.92 & & $0.51 \%$ \\
\hline Case 11 (5-3-5-15) & 745,385 & 378.24 & 735,503 & 191.68 & 9,882 & $1.33 \%$ \\
\hline Case 12 (5-3-5-15) & 811,106 & 92.01 & 727,251 & 88.86 & 83,855 & $10.34 \%$ \\
\hline Case $13(5-3-5-15)$ & 988,571 & 419.46 & 919,670 & 403.44 & 68,901 & $6.97 \%$ \\
\hline Case 14 (5-3-5-15) & 974,342 & 351.94 & 919,175 & 343.47 & 55,167 & $5.66 \%$ \\
\hline Case 15 (5-3-5-15) & 833,043 & 900.64 & 832,979 & 90.82 & 64 & $0.01 \%$ \\
\hline Case 16 (5-3-5-15) & 845,915 & 180.74 & 818,642 & 160.75 & 27,273 & $3.22 \%$ \\
\hline Case 17 (5-3-5-15) & 735,539 & 98.76 & 735,334 & 92.62 & 205 & $0.03 \%$ \\
\hline Case 18 (5-3-5-15) & 917,953 & 50.82 & 858,491 & 50.82 & 59,462 & $6.48 \%$ \\
\hline Case 19 (5-3-5-15) & No solution found & - & 977,396 & 191.88 & - & $\begin{array}{c}\text { Only } \\
\text { Linear } \\
\text { Solution }\end{array}$ \\
\hline Case $20(5-3-5-15)$ & 971,726 & $876,959.40$ & 855,959 & 150.08 & 115,767 & $11.91 \%$ \\
\hline AVERAGE & 869,287 & $97,714.66$ & 822,556 & 174.73 & & $5.11 \%$ \\
\hline Case $21(7-3-5-20)$ & No solution found & - & $1,051,772$ & 597.58 & - & $\begin{array}{c}\text { Only } \\
\text { Linear } \\
\text { Solution }\end{array}$ \\
\hline Case 22 (7-3-5-20) & 993,942 & $1,587.54$ & 974,498 & 461.08 & 19,444 & $1.96 \%$ \\
\hline Case 23 (7-3-5-20) & $1,274,019$ & $212,939.00$ & $1,269,256$ & $1,636.17$ & 4,763 & $0.37 \%$ \\
\hline Case 24 (7-3-5-20) & $1,285,862$ & $1,636.40$ & $1,268,819$ & $1,454.15$ & 17,043 & $1.33 \%$ \\
\hline Case 25 (7-3-5-20) & No solution found & - & $1,062,143$ & $1,986.87$ & - & $\begin{array}{c}\text { Only } \\
\text { Linear } \\
\text { Solution }\end{array}$ \\
\hline Case 26 (7-3-5-20) & $1,051,350$ & $16,621.00$ & $1,051,299$ & 859.15 & 51 & $0.00 \%$ \\
\hline Case 27 (7-3-5-20) & 976,769 & $3,850.00$ & 974,422 & 589.93 & 2,347 & $0.24 \%$ \\
\hline Case 28 (7-3-5-20) & $1,112,979$ & $28,959.00$ & $1,112,397$ & 611.73 & 582 & $0.05 \%$ \\
\hline Case 29 (7-3-5-20) & No solution found & - & $1,221,641$ & $1,374.21$ & - & $\begin{array}{c}\text { Only } \\
\text { Linear } \\
\text { Solution }\end{array}$ \\
\hline Case 30 (7-3-5-20) & No solution found & - & $1,269,527$ & 693.48 & - & $\begin{array}{c}\text { Only } \\
\text { Linear } \\
\text { Solution }\end{array}$ \\
\hline AVERAGE & $1,115,820$ & $44,265.49$ & $1,108,449$ & 935.37 & & $0.66 \%$ \\
\hline Case 31 (10-3-5-20) & 980,256 & $4,228.34$ & 979,306 & $2,829.46$ & 950 & $0.10 \%$ \\
\hline Case 32 (10-3-5-20) & 831,262 & $3,300.00$ & 831,094 & $1,531.48$ & 168 & $0.02 \%$ \\
\hline Case 33 (10-3-5-20) & $1,106,338$ & $6,568.55$ & $1,106,338$ & $3,234.91$ & 0 & $0.00 \%$ \\
\hline Case 34 (10-3-5-20) & No solution found & - & $1,108,531$ & $2,508.82$ & - & $\begin{array}{c}\text { Only } \\
\text { Linear } \\
\text { Solution }\end{array}$ \\
\hline Case 35 (10-3-5-20) & No solution found & - & $1,050,292$ & $1,279.51$ & - & $\begin{array}{c}\text { Only } \\
\text { Linear } \\
\text { Solution }\end{array}$ \\
\hline
\end{tabular}


TABLe 7: Continued.

\begin{tabular}{|c|c|c|c|c|c|c|}
\hline \multirow{2}{*}{$\begin{array}{l}\text { Case \# } \\
\text { (Instance size) }\end{array}$} & \multicolumn{2}{|c|}{ Non-Linear Model 4EILP-SS } & \multicolumn{2}{|c|}{ Linear Model 4EILP-SS-L } & \multicolumn{2}{|c|}{ Saving } \\
\hline & $\begin{array}{l}\text { Best found objective } \\
\text { function value (Z1) }\end{array}$ & $\begin{array}{l}\text { Elapsed run time } \\
\text { (sec) }\end{array}$ & $\begin{array}{l}\text { Best found objective } \\
\text { function value (Z2) }\end{array}$ & $\begin{array}{l}\text { Elapsed run time } \\
(\mathrm{sec})\end{array}$ & Saved Cost & \% Saving \\
\hline Case 36 (10-3-5-20) & 975,718 & $1,786.84$ & 975,705 & $3,503.63$ & 13 & $0.00 \%$ \\
\hline Case 37 (10-3-5-20) & 845,102 & $3,327.00$ & 824,554 & 594.98 & 20,548 & $2.43 \%$ \\
\hline Case 38 (10-3-5-20) & No solution found & - & 976,929 & $1,151.09$ & - & $\begin{array}{c}\text { Only } \\
\text { Linear } \\
\text { Solution }\end{array}$ \\
\hline Case 39 (10-3-5-20) & No solution found & - & $1,109,935$ & $3,214.58$ & - & $\begin{array}{c}\text { Only } \\
\text { Linear } \\
\text { Solution }\end{array}$ \\
\hline Case $40(10-3-5-20)$ & No solution found & - & $1,109,484$ & $3,532.16$ & - & $\begin{array}{c}\text { Only } \\
\text { Linear } \\
\text { Solution }\end{array}$ \\
\hline AVERAGE & 947,735 & $3,842.15$ & 943,399 & $2,338.89$ & & $0.51 \%$ \\
\hline Case 41 (10-3-5-25) & $1,270,846$ & 923.97 & $1,270,708$ & 982.18 & 138 & $0.01 \%$ \\
\hline Case $42(10-3-5-25)$ & No solution found & - & $1,106,664$ & 1381.60 & - & $\begin{array}{c}\text { Only } \\
\text { Linear } \\
\text { Solution }\end{array}$ \\
\hline Case 43 (10-3-5-25) & $1,281,643$ & $8,552.48$ & $1,278,946$ & $4,756.29$ & 2,697 & $0.21 \%$ \\
\hline Case 44 (10-3-5-25) & $1,280,408$ & $2,266.26$ & $1,280,802$ & $3,530.13$ & -394 & $-0.03 \%$ \\
\hline Case 45 (10-3-5-25) & $1,417,022$ & $6,783.66$ & $1,266,151$ & $3,295.30$ & 150,871 & $10.65 \%$ \\
\hline Case 46 (10-3-5-25) & $1,140,753$ & $8,476.40$ & $1,130,751$ & 819.56 & 10,002 & $0.88 \%$ \\
\hline Case 47 (10-3-5-25) & No solution found & - & $1,127,784$ & $1,273.77$ & - & $\begin{array}{c}\text { Only } \\
\text { Linear } \\
\text { Solution }\end{array}$ \\
\hline Case 48 (10-3-5-25) & No solution found & - & $1,433,556$ & $7,271.13$ & - & $\begin{array}{c}\text { Only } \\
\text { Linear } \\
\text { Solution }\end{array}$ \\
\hline Case 49 (10-3-5-25) & No solution found & - & $1,277,243$ & $3,500.21$ & - & $\begin{array}{c}\text { Only } \\
\text { Linear } \\
\text { Solution }\end{array}$ \\
\hline Case 50 (10-3-5-25) & $1,268,140$ & $7,441.08$ & $1,266,054$ & 954.83 & 2,086 & $0.16 \%$ \\
\hline AVERAGE & $1,276,469$ & $5,740.64$ & $1,248,902$ & $2,389.72$ & & $2.38 \%$ \\
\hline
\end{tabular}

of performance of the nonlinear model goes from $50 \%$ to $100 \%$ among the instances. Using the linear model an optimal solution was obtained in all cases. For these instance sizes, one can be confident in obtaining a good solution with the linear model, which is not the case with the nonlinear model.

\section{Conclusions and Final Remarks}

This research introduced an inventory-location model, 4EILP-SS, for the network design of a four-echelon supply chain, considering the location of warehouses and plants, transportation cost, inventory costs, and supplier selection. The inventory policy and network design decisions are tactical and strategic decisions that should be analyzed concurrently. This is attained using the aforementioned model. This model can be applied to design complex and long supply chains, like in the automotive industry because of the offshore movement of production facilities from industrialized countries to emerging economies. In many cases, there is infrastructure available in the country, and it is easy to adapt the model to that situation fixing locations for the available facilities and allowing the model to decide for the new optimum flows and locations of new facilities.

The model proposed becomes nonlinear because of the application of the continuous review inventory policy. This feature added to the computational complexity inherited from the Facility Location Problem makes the problem hard to solve. The mixed integer nonlinear model was reformulated using a piecewise linear function and a reformulation of nonlinear constraints in order to generate a mixed integer linear model. Several instances were solved using the linear and nonlinear models, comparing the results in terms of cost savings, number of solutions obtained, and computational runtime. It was observed that solving the nonlinear model with the commercial software generated local optimal solutions, and in several cases the software either did not converge or resulted in infeasible solutions. The total cost of the original objective function is lower, in most of the cases, with the solution obtained by the linear model than the solution obtained by the nonlinear model.

The main contribution of the paper is two-fold. Firstly, a network optimization model for a particular four level 
TABLE 8: Structure of the supply chain applying the nonlinear model and the linear model considering a service level of $95 \%$.

\begin{tabular}{|c|c|c|c|c|}
\hline \multirow{2}{*}{$\begin{array}{l}\text { Case \# } \\
\text { (Instance size) }\end{array}$} & \multicolumn{2}{|c|}{ Non-Linear Model 4EILP-SS } & \multicolumn{2}{|c|}{ Linear Model 4EILP-SS-L } \\
\hline & $\begin{array}{c}\text { Number of plants } \\
\text { selected }\end{array}$ & $\begin{array}{c}\text { Number of } \\
\text { warehouses selected }\end{array}$ & $\begin{array}{c}\text { Number of plants } \\
\text { selected }\end{array}$ & $\begin{array}{c}\text { Number of } \\
\text { warehouses selected }\end{array}$ \\
\hline Case $1(5-3-5-10)$ & 3 & 4 & 3 & 5 \\
\hline Case $2(5-3-5-10)$ & 3 & 5 & 3 & 5 \\
\hline Case $3(5-3-5-10)$ & 2 & 4 & 2 & 4 \\
\hline Case 4 (5-3-5-10) & 2 & 3 & 2 & 3 \\
\hline Case 5 (5-3-5-10) & 3 & 4 & 3 & 5 \\
\hline Case 6 (5-3-5-10) & 3 & 4 & 3 & 5 \\
\hline Case 7 (5-3-5-10) & 3 & 4 & 3 & 5 \\
\hline Case 8 (5-3-5-10) & 3 & 4 & 3 & 5 \\
\hline Case $9(5-3-5-10)$ & 2 & 3 & 2 & 4 \\
\hline Case $10(5-3-5-10)$ & 3 & 4 & 3 & 4 \\
\hline Case 11( 5-3-5-15) & 3 & 4 & 3 & 4 \\
\hline Case $12(5-3-5-15)$ & 2 & 4 & 3 & 4 \\
\hline Case 13 (5-3-5-15) & 2 & 3 & 2 & 3 \\
\hline Case $14(5-3-5-15)$ & 2 & 3 & 2 & 3 \\
\hline Case 15 (5-3-5-15) & 2 & 4 & 2 & 4 \\
\hline Case 16 (5-3-5-15) & 2 & 4 & 2 & 4 \\
\hline Case 17 (5-3-5-15) & 3 & 4 & 3 & 4 \\
\hline Case $18(5-3-5-15)$ & 2 & 3 & 2 & 4 \\
\hline Case 19 (5-3-5-15) & No solution found & - & 2 & 3 \\
\hline Case 20 (5-3-5-15) & 2 & 3 & 2 & 4 \\
\hline Case 21 (7-3-5-20) & No solution found & - & 2 & 4 \\
\hline Case $22(7-3-5-20)$ & 3 & 4 & 3 & 4 \\
\hline Case 23 (7-3-5-20) & 2 & 3 & 2 & 3 \\
\hline Case 24 (7-3-5-20) & 2 & 3 & 2 & 3 \\
\hline Case 25 (7-3-5-20) & No solution found & - & 2 & 4 \\
\hline Case 26 (7-3-5-20) & 2 & 4 & 2 & 4 \\
\hline Case 27 (7-3-5-20) & 3 & 4 & 3 & 4 \\
\hline Case 28 (7-3-5-20) & 2 & 3 & 2 & 4 \\
\hline Case 29 (7-3-5-20) & No solution found & - & 2 & 3 \\
\hline Case $30(7-3-5-20)$ & No solution found & - & 2 & 3 \\
\hline Case 31 (10-3-5-20) & 2 & 3 & 2 & 4 \\
\hline Case $32(10-3-5-20)$ & 3 & 4 & 3 & 4 \\
\hline Case 33 (10-3-5-20) & 2 & 3 & 2 & 3 \\
\hline Case 34 (10-3-5-20) & No solution found & - & 2 & 3 \\
\hline Case 35 (10-3-5-20) & No solution found & - & 2 & 3 \\
\hline Case 36 (10-3-5-20) & 2 & 3 & 2 & 4 \\
\hline Case $37(10-3-5-20)$ & 3 & 4 & 3 & 4 \\
\hline Case 38 (10-3-5-20) & No solution found & - & 2 & 4 \\
\hline Case $39(10-3-5-20)$ & No solution found & - & 2 & 3 \\
\hline Case 40 (10-3-5-20) & No solution found & - & 2 & 3 \\
\hline Case 41 (10-3-5-25) & 2 & 3 & 2 & 4 \\
\hline Case 42 (10-3-5-25) & No solution found & - & 3 & 4 \\
\hline Case 43 (10-3-5-25) & 2 & 3 & 2 & 4 \\
\hline Case 44 (10-3-5-25) & 2 & 3 & 2 & 4 \\
\hline Case 45 (10-3-5-25) & 2 & 3 & 2 & 4 \\
\hline Case 46 (10-3-5-25) & 2 & 4 & 3 & 4 \\
\hline
\end{tabular}


TABLE 8: Continued.

\begin{tabular}{|c|c|c|c|c|}
\hline \multirow{2}{*}{$\begin{array}{l}\text { Case \# } \\
\text { (Instance size) }\end{array}$} & \multicolumn{2}{|c|}{ Non-Linear Model 4EILP-SS } & \multicolumn{2}{|c|}{ Linear Model 4EILP-SS-L } \\
\hline & $\begin{array}{c}\text { Number of plants } \\
\text { selected }\end{array}$ & $\begin{array}{c}\text { Number of } \\
\text { warehouses selected }\end{array}$ & $\begin{array}{c}\text { Number of plants } \\
\text { selected }\end{array}$ & $\begin{array}{c}\text { Number of } \\
\text { warehouses selected }\end{array}$ \\
\hline Case 47 (10-3-5-25) & No solution found & - & 3 & 4 \\
\hline Case 48 (10-3-5-25) & No solution found & - & 2 & 3 \\
\hline Case 49 (10-3-5-25) & No solution found & - & 2 & 4 \\
\hline Case $50(10-3-5-25)$ & 2 & 3 & 2 & 4 \\
\hline
\end{tabular}

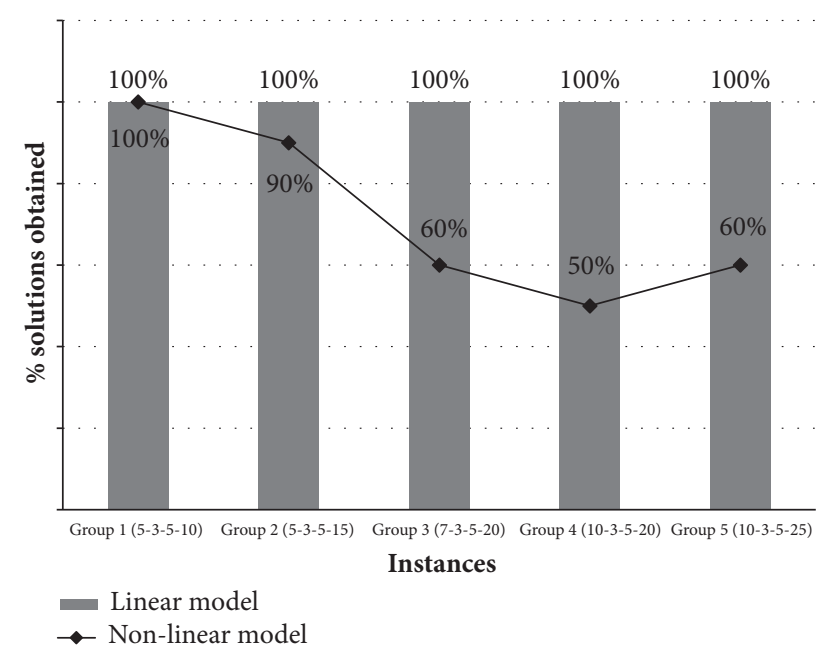

FIGURE 5: Percent of solutions obtained, comparing nonlinear versus linear models.

supply chain, where facility location and inventory management decisions are considered in two stages (plants and warehouses), and transportation or assignment decisions are modeled in three stages of the supply chain, i.e., suppliersplants, plants-warehouses, and warehouses-customers. Secondly, a linearization approach of the proposed nonlinear model, in order to facilitate its applicability and its effective and efficient implementation, improves both solutions quality and computational times.

The proposed linear model proves to be useful for decision makers interested in analyzing and designing supply chain networks with the structure of a 4EILP-SS. The problem can be analyzed and solved in a short period of time and with significant confidence in the solution quality.

The experiments conducted allowed us to understand the complexity of the problem. For this study, LINGO was used to solve the linear and the nonlinear models, but future work may take advantage of using more efficient commercial software to solve larger instances. As observed, using commercial optimizers may not be the best alternative when it comes to solve very large instances. Therefore, immediate future research should consider the development of other heuristics aimed to tackle large instances (Lagrangian relaxation, Bender decompositions, Cutting planes, and Metaheuristics). Another direction is to extend the pricing approach proposed by Shu et al. [18] to solve a similar problem to the long supply chain proposed in this paper.
In addition, a deeper study may involve the analysis of the relations between parameters like costs, capacities, lead times, and demand variability, to understand their impact in the supply chain network configuration.

Finally, it would be interesting to extend the model to analyze multiobjective situations, more common when designing supply chain networks for real situations.

\section{Data Availability}

The data used to support the findings of this study are available from the corresponding author upon request.

\section{Conflicts of Interest}

The authors declare that there are no conflicts of interest regarding the publication of this article.

\section{Acknowledgments}

This research was supported by Programa para el Mejoramiento del Profesorado PROMEP (Grant ITESUR001 Charter no. PROMEP/103.5/10/5709) and Universidad Panamericana (Grant no. UP-CI-2018-ING-GDL-06).

\section{References}

[1] M. Mourits and J. J. Evers, "Distribution network design: an integrated planning support framework," Logistics Information Management, vol. 9, pp. 45-54, 1995.

[2] R. Z. Farahani, H. Rashidi Bajgan, B. Fahimnia, and M. Kaviani, "Location-inventory problem in supply chains: A modelling review," International Journal of Production Research, vol. 53, no. 12, pp. 3769-3788, 2015.

[3] OICA, International Organization of Motor Vehicle Manufacturers, Production statistics, 2017, http://www.oica.net/ category/production-statistics/2017-statistics/.

[4] H. Hamacher and Z. Drezner, Facility Location: Applications and Theory, Springer, Berlin, Germany, 2002.

[5] M. S. Daskin, Network and Discrete Location: Models, Algorithms, and Applications, Wiley-Interscience, New York, NY, USA, 1st edition, 1995.

[6] S. Nickel and J. Puerto, Location Theory: A Unified Approach, Springer, New York, NY, USA, 2005.

[7] M. T. Melo, S. Nickel, and F. Saldanha-da-Gama, "Facility location and supply chain management-a review," European Journal of Operational Research, vol. 196, no. 2, pp. 401-412, 2009. 
[8] H. A. Eiselt and V. Marianov, Foundations of Location Analysis, Springer, New York, NY, USA, 2011.

[9] H. A. Eiselt and V. Marianov, Applications of Location Analysis, Springer, New York, NY, USA, 2015.

[10] V. Jayaraman, "Transportation, facility location and inventory issues in distribution network design: An investigation," International Journal of Operations and Production Management, vol. 18, no. 5, pp. 471-494, 1998.

[11] L. K. Nozick and M. A. Turnquist, "Integrating inventory impacts into a fixed-charge model for locating distribution centers," Transportation Research Part E: Logistics and Transportation Review, vol. 34, no. 3, pp. 173-186, 1998.

[12] S. J. Erlebacher and R. D. Meller, "The interaction of location and inventory in designing distribution systems," IIE Transactions, vol. 32, no. 2, pp. 155-166, 2000.

[13] L. K. Nozick and M. A. Turnquist, "A two-echelon inventory allocation and distribution center location analysis," Transportation Research Part E: Logistics and Transportation Review, vol. 37, no. 6, pp. 425-441, 2001.

[14] L. K. Nozick and M. A. Turnquist, "Inventory, transportation, service quality and the location of distribution centers," European Journal of Operational Research, vol. 129, no. 2, pp. 362-371, 2001.

[15] M. S. Daskin, C. R. Coullard, and Z. J. M. Shen, “An inventorylocation model: formulation, solution algorithm and computational results," Annals of Operations Research, vol. 110, pp. 83106, 2002.

[16] Z.-J. M. Shen, C. R. Coullard, and M. S. Daskin, "A joint location-inventory model," Transportation Science, vol. 37, no. 1, pp. 40-55, 2003.

[17] P. A. Miranda and R. A. Garrido, "Incorporating inventory control decisions into a strategic distribution network design model with stochastic demand," Transportation Research Part E: Logistics and Transportation Review, vol. 40, no. 3, pp. 183-207, 2004.

[18] J. Shu, C.-P. Teo, and Z. M. Shen, "Stochastic transportationinventory network design problem," Operations Research, vol. 53, no. 1, pp. 48-60, 2005.

[19] L. V. Snyder, M. S. Daskin, and C.-P. Teo, "The stochastic location model with risk pooling," European Journal of Operational Research, vol. 179, no. 3, pp. 1221-1238, 2007.

[20] J. Shu, Q. Ma, and S. Li, "Integrated location and two-echelon inventory network design under uncertainty," Annals of Operations Research, vol. 181, pp. 233-247, 2010.

[21] P. A. Miranda and R. A. Garrido, "A simultaneous inventory control and facility location model with stochastic capacity constraints," Networks and Spatial Economics, vol. 6, no. 1, pp. 39-53, 2006.

[22] P. A. Miranda and R. A. Garrido, "Valid inequalities for Lagrangian relaxation in an inventory location problem with stochastic capacity," Transportation Research Part E: Logistics and Transportation Review, vol. 44, no. 1, pp. 47-65, 2008.

[23] L. Ozsen, C. R. Coullard, and M. S. Daskin, "Capacitated warehouse location model with risk pooling," Naval Research Logistics (NRL), vol. 55, no. 4, pp. 295-312, 2008.

[24] P. A. Miranda and G. Cabrera, "Inventory location problem with stochastic capacity constraints under periodic review $(R, s$, S)," in Proceedings of the International Conference on Industrial Logistics: Logistics and Sustainability, (ICIL '10), pp. 289-296, 2010.
[25] G. Cabrera, P. A. Miranda, E. Cabrera et al., "Solving a novel inventory location model with stochastic constraints and inventory control policy," Mathematical Problems in Engineering, vol. 2013, Article ID 670528, 12 pages, 2013.

[26] J.-H. Kang and Y.-D. Kim, "Inventory control in a two-level supply chain with risk pooling effect," International Journal of Production Economics, vol. 135, no. 1, pp. 116-124, 2012.

[27] F. Silva and L. Gao, "A joint replenishment inventory-location model," Networks and Spatial Economics, vol. 13, no. 1, pp. 107122,2013

[28] J.-S. Tancrez, J.-C. Lange, and P. Semal, "A location-inventory model for large three-level supply chains," Transportation Research Part E: Logistics and Transportation Review, vol. 48, no. 2, pp. 485-502, 2012.

[29] A. Diabat, J.-P. Richard, and C. . Codrington, "A Lagrangian relaxation approach to simultaneous strategic and tactical planning in supply chain design," Annals of Operations Research, vol. 203, pp. 55-80, 2013.

[30] M. Shahabi, S. Akbarinasaji, A. Unnikrishnan, and R. James, "Integrated inventory control and facility location decisions in a multi-echelon supply chain network with hubs," Networks and Spatial Economics, vol. 13, pp. 497-514, 2013.

[31] Z.-J. M. Shen and M. S. Daskin, “Trade-offs between customer service and cost in integrated supply chain design," Manufacturing and Service Operations Management, vol. 7, no. 3, pp. 188207, 2005.

[32] S. Gaur and A. R. Ravindran, "A bi-criteria model for the inventory aggregation problem under risk pooling," Computers \& Industrial Engineering, vol. 51, no. 3, pp. 482-501, 2006.

[33] P. A. Miranda and R. A. Garrido, "Inventory service-level optimization within distribution network design problem," International Journal of Production Economics, vol. 122, no. 1, pp. 276-285, 2009.

[34] H.-Y. Mak and Z. M. Shen, "A two-echelon inventory-location problem with service considerations," Naval Research Logistics (NRL), vol. 56, no. 8, pp. 730-744, 2009.

[35] P. Escalona, F. Ordóñez, and V. Marianov, "Joint locationinventory problem with differentiated service levels using critical level policy," Transportation Research Part E: Logistics and Transportation Review, vol. 83, pp. 141-157, 2015.

[36] A. Atamtürk, G. Berenguer, and Z.-J. Shen, "A conic integer programming approach to stochastic joint location-inventory problems," Operations Research, vol. 60, no. 2, pp. 366-381, 2012.

[37] O. Kaya and B. Urek, "A mixed integer nonlinear programming model and heuristic solutions for location, inventory and pricing decisions in a closed loop supply chain," Computers \& Operations Research, vol. 65, pp. 93-103, 2016.

[38] M. a. Schuster Puga and J.-S. Tancrez, "A heuristic algorithm for solving large location-inventory problems with demand uncertainty," European Journal of Operational Research, vol. 259, no. 2, pp. 413-423, 2017.

[39] P. Escalona, V. Marianov, F. Ordóñez, and R. Stegmaier, “On the effect of inventory policies on distribution network design with several demand classes," Transportation Research Part E: Logistics and Transportation Review, vol. 111, pp. 229-240, 2018.

[40] F. J. Tapia-Ubeda, P. A. Miranda, and M. Macchi, "A generalized Benders decomposition based algorithm for an inventory location problem with stochastic inventory capacity constraints," European Journal of Operational Research, vol. 267, no. 3, pp. 806-817, 2018. 
[41] R. E. Perez Loaiza, E. Olivares-Benitez, P. A. Miranda Gonzalez, A. Guerrero Campanur, and J. L. Martinez Flores, "Supply chain network design with efficiency, location, and inventory policy using a multiobjective evolutionary algorithm," International Transactions in Operational Research, vol. 24, no. 1-2, pp. 251275, 2017.

[42] F. You and I. E. Grossmann, "Integrated multi-echelon supply chain design with inventories under uncertainty: MINLP models, computational strategies," AIChE Journal, vol. 56, no. 2, pp. 419-440, 2010.

[43] K. Petridis, "Optimal design of multi-echelon supply chain networks under normally distributed demand," Annals of Operations Research, vol. 227, no. 1, pp. 63-91, 2015.

[44] A. Diabat and E. Theodorou, "A location-inventory supply chain problem: Reformulation and piecewise linearization," Computers \& Industrial Engineering, vol. 90, pp. 381-389, 2015.

[45] A. Nyberg, I. E. Grossmann, and T. Westerlund, "An efficient reformulation of the multiechelon stochastic inventory system with uncertain demands," AIChE Journal, vol. 59, no. 1, pp. 2328, 2013. 


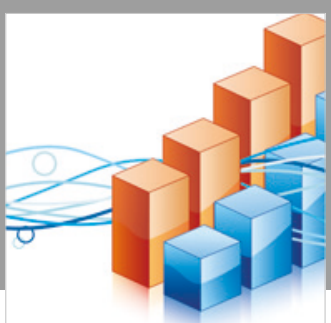

Advances in

Operations Research

\section{-n-m}
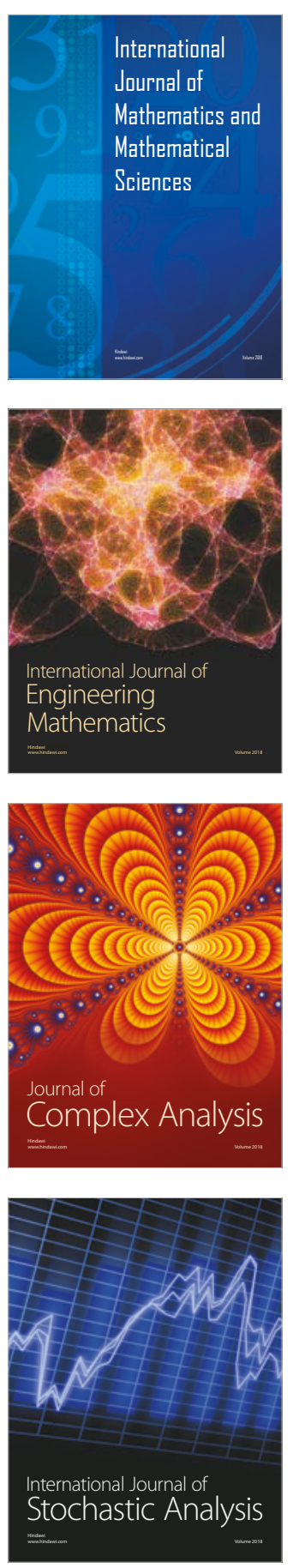
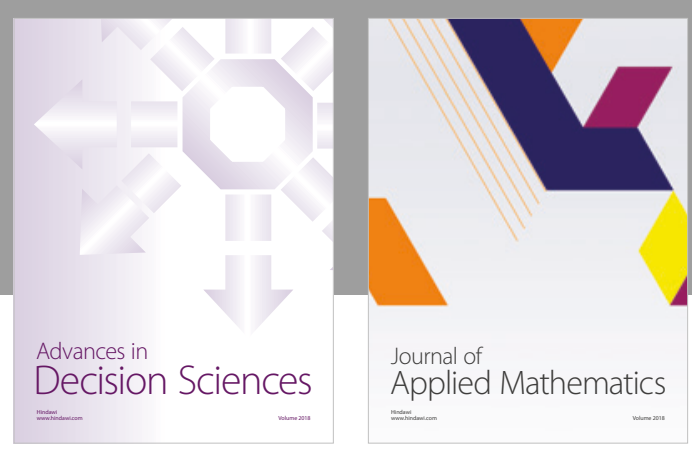

Journal of

Applied Mathematics
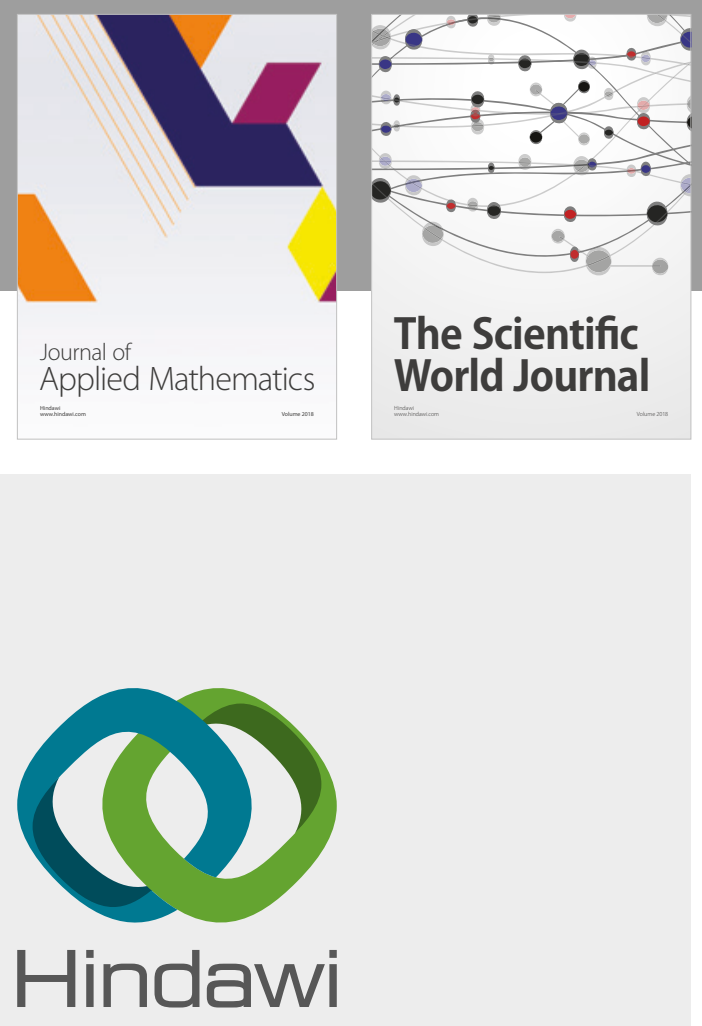

Submit your manuscripts at

www.hindawi.com

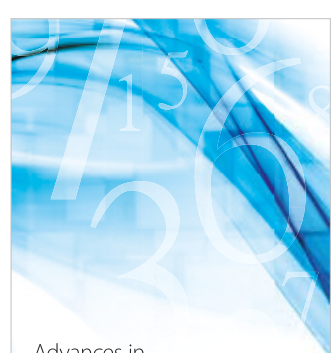

Advances in
Numerical Analysis
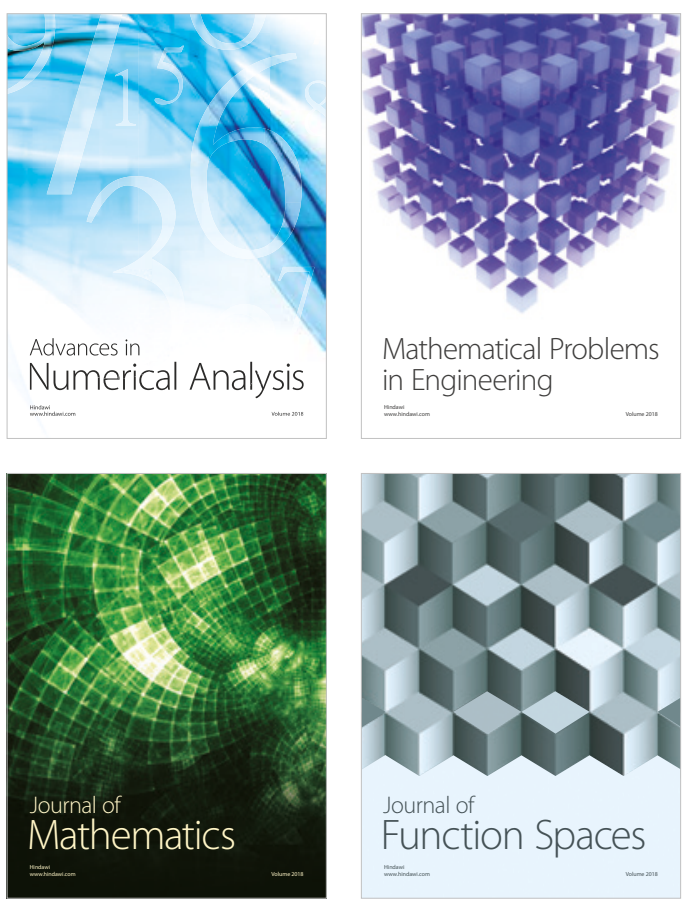

Mathematical Problems in Engineering

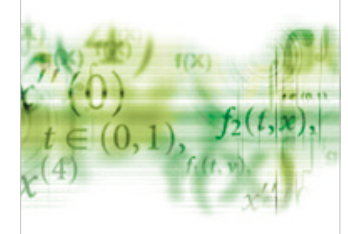

International Journal of

Differential Equations

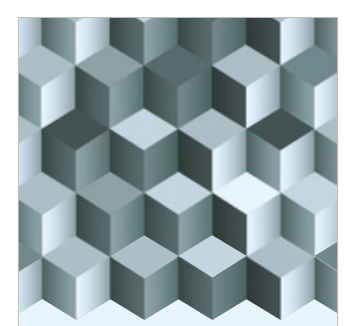

Journal of

Function Spaces
The Scientific

World Journal

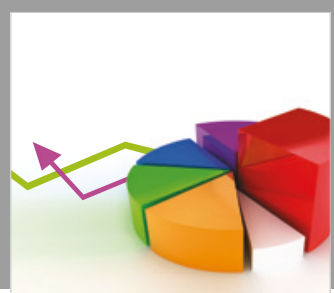

Journal of

Probability and Statistics
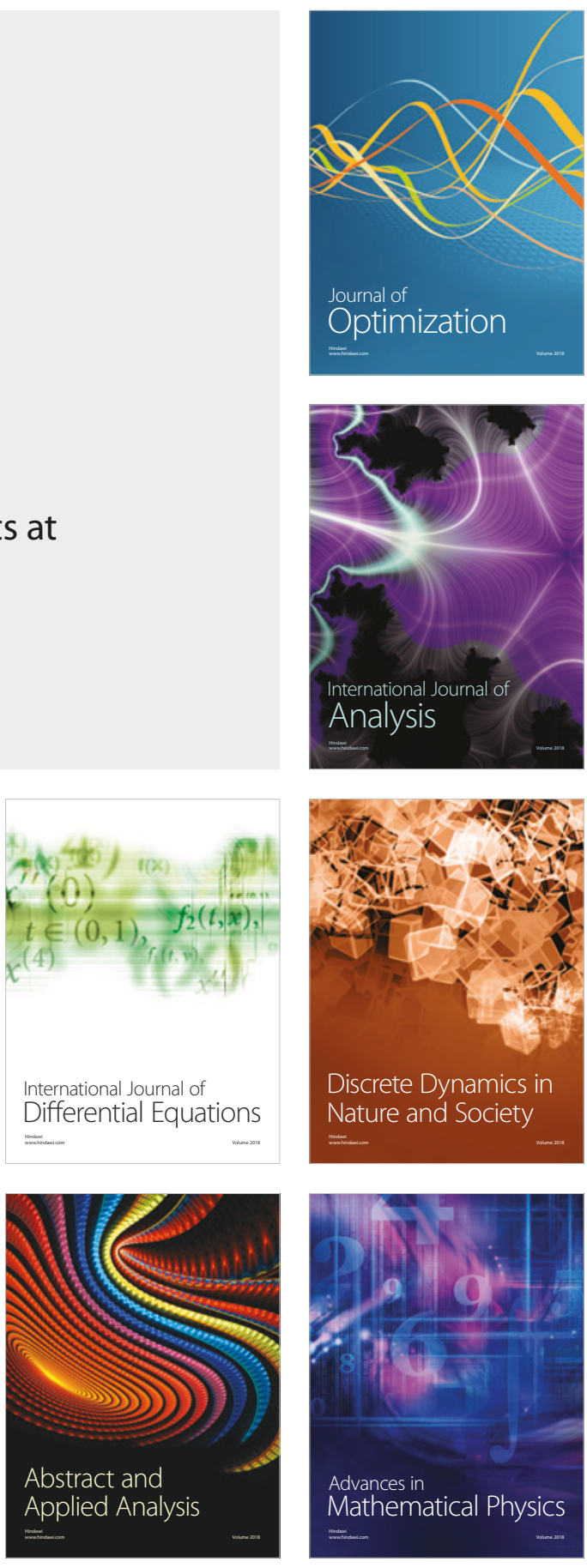